\title{
Domino Knoevenagel hetero Diels-Alder reactions of sugar derived $\delta, \varepsilon$-unsaturated aldehydes
}

\author{
John K. Gallos*and Alexandros E. Koumbis \\ Department of Chemistry, Aristotle University of Thessaloniki, Thessaloniki, GR 54124, Greece \\ E-mail: igallos@chem.auth.gr
}

Dedicated to Professor Anastasios Varvoglis on the occasion of his $65^{\text {th }}$ birthday

(received 01 Feb 03; accepted 25 Apr 03; published on the web 08 May 03)

\begin{abstract}
$\delta, \varepsilon$-Unsaturated aldehydes prepared from $D$-glucose and $D$-ribose served as suitable substrates in intramolecular domino Knoevenagel hetero Diels-Alder reactions with $N, N$-dimethylbarbituric acid yielding polyhydroxylated carbocycle-dihydropyran fused ring systems.
\end{abstract}

Keywords: Domino Knoevenagel hetero Diels-Alder reaction, $\delta, \varepsilon$-unsaturated aldehydes, carbocycles

\section{Introduction}

During the last decades a great number of domino (or tandem) reactions has been evolved. ${ }^{1}$ These versatile synthetic tools were wisely used for the synthesis of structurally diverse compounds along with biologically active natural products and drugs. ${ }^{2-4}$ One of the most fruitful categories, described as the domino Knoevenagel hetero Diels-Alder approach (DKHDA), involves a sequence of two in depth investigated and well recognized reactions. ${ }^{5-6}$ Tietze and his co-workers ${ }^{2-4,7-8}$ extensively studied and exploited this particularly simple way to construct fused heterocycles, usually in a stereoselective manner. Other groups also thoroughly employed this key sequence in their synthetic efforts. ${ }^{9-13}$ Prompted by our continuing interest in building carbocycles from carbohydrates ${ }^{14}$ we decided to explore the possibility of preparing novel carbocyclic derivatives through the intramolecular DKHDA approach following the retrosynthetic itinerary depicted in Scheme 1. 


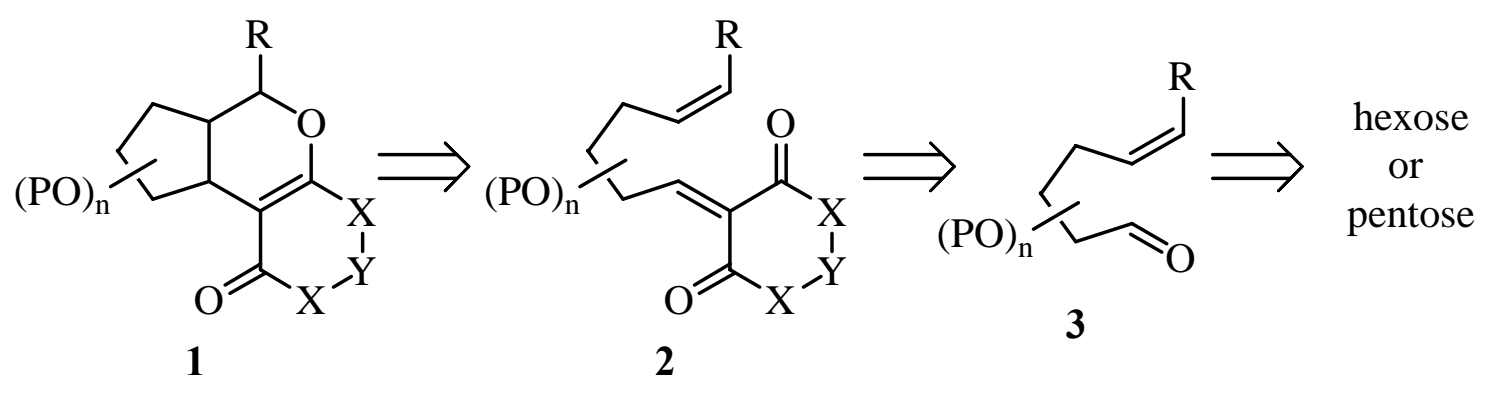

Scheme 1. Retrosynthetic analysis.

According to this, a polyhydroxylated carbocycle-dihydropyran fused ring system $\mathbf{1}$ could be obtained applying a Knoevenagel condensation of $\delta$, $\varepsilon$-unsaturated aldehydes $\mathbf{3}$ with appropriate 1,3-dicarbonyl components to form intermediates $\mathbf{2}$, followed by an intramolecular hetero DielsAlder cycloaddition reaction. In turn, aldehydes $\mathbf{3}$ could be synthesized from an hexose or a pentose.

\section{Results and Discussion}

To investigate the feasibility of our plan we chose to perform our reactions with three extensively studied 1,3-dicarbonyl compounds: $N, N$-dimethylbarbituric acid, 4, Meldrum's acid, 5, and dimedone, 6, (Figure 1) are readily available symmetrical reagents, which were often employed in DKHDA reactions with good results. ${ }^{7}$
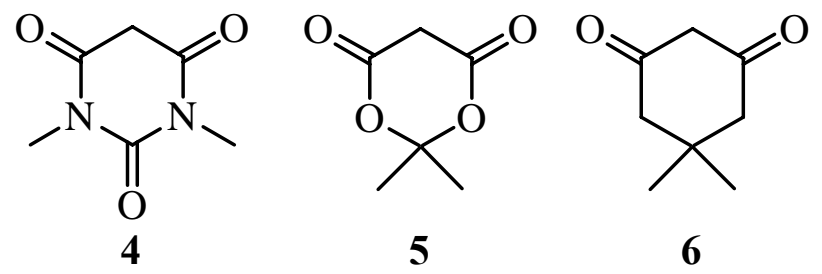

Figure 1. Structures of selected 1,3-dicarbonyl components for DKHDA reactions.

The required $\delta, \varepsilon$-unsaturated aldehydes 8 (Scheme 2) and $\mathbf{1 4}$ (Scheme 3) were prepared from the corresponding iodide $\mathbf{7}$ and alcohol 13, respectively, and used without isolation in the domino reactions. Precursors $\mathbf{7}$ and $\mathbf{1 3}$ are derivatives of $D$-glucose and $D$-ribose; easily accessible following well established procedures. ${ }^{14 \mathrm{e}}$

Tietze's general protocol $^{8 \mathrm{~d}}$ which involves catalysis of ethylenediamine diacetate (EDDA) and the presence of a dehydrating agent was followed using initially the most reactive of the 1,3dicarbonyl compounds shown in Figure 1, barbituric acid derivative 4. Reactions were found to proceed smoothly under refluxing conditions in acetonitrile with both sugar derived candidates affording the desired cycloadducts in average overall yields from iodide $\mathbf{7}$ and alcohol $\mathbf{1 3}$ (Scheme 2 and Scheme 3). 
Careful investigation of the reaction mixture obtained from the monosubstituted olefin $\mathbf{8}$ revealed the presence of three products (Scheme 2). The minor one was easily separated from the other two isomers using column chromatography and was found to be the regioisomeric product with the bridged structure of $\mathbf{1 2}$. The other two products (diastereoisomers $\mathbf{1 0}$ and $\mathbf{1 1}$ ), formed almost in equimolar quantities, were subsequently separated on PTLC.

A mixture of products was also obtained from the domino reaction of the 1,2-disubstituted olefin 14 through the Knoevenagel intermediate 15 (Scheme 3). This mixture was actually found to contain the major product $\mathbf{1 6}$ along with two unidentified products (most likely diasteroisomers) in less than $5 \%$ of the total amount. The presence of the unknown compounds could be easily detected in the ${ }^{1} \mathrm{H}$ NMR spectra where two extra couples of singlets were observed in the area of $N$-methyl groups ( $\delta 3.49,3.47$ and 3.15, 3.13). However, all chromatographic efforts to obtain pure samples of the major product and the possible diasteroisomers were proved futile.

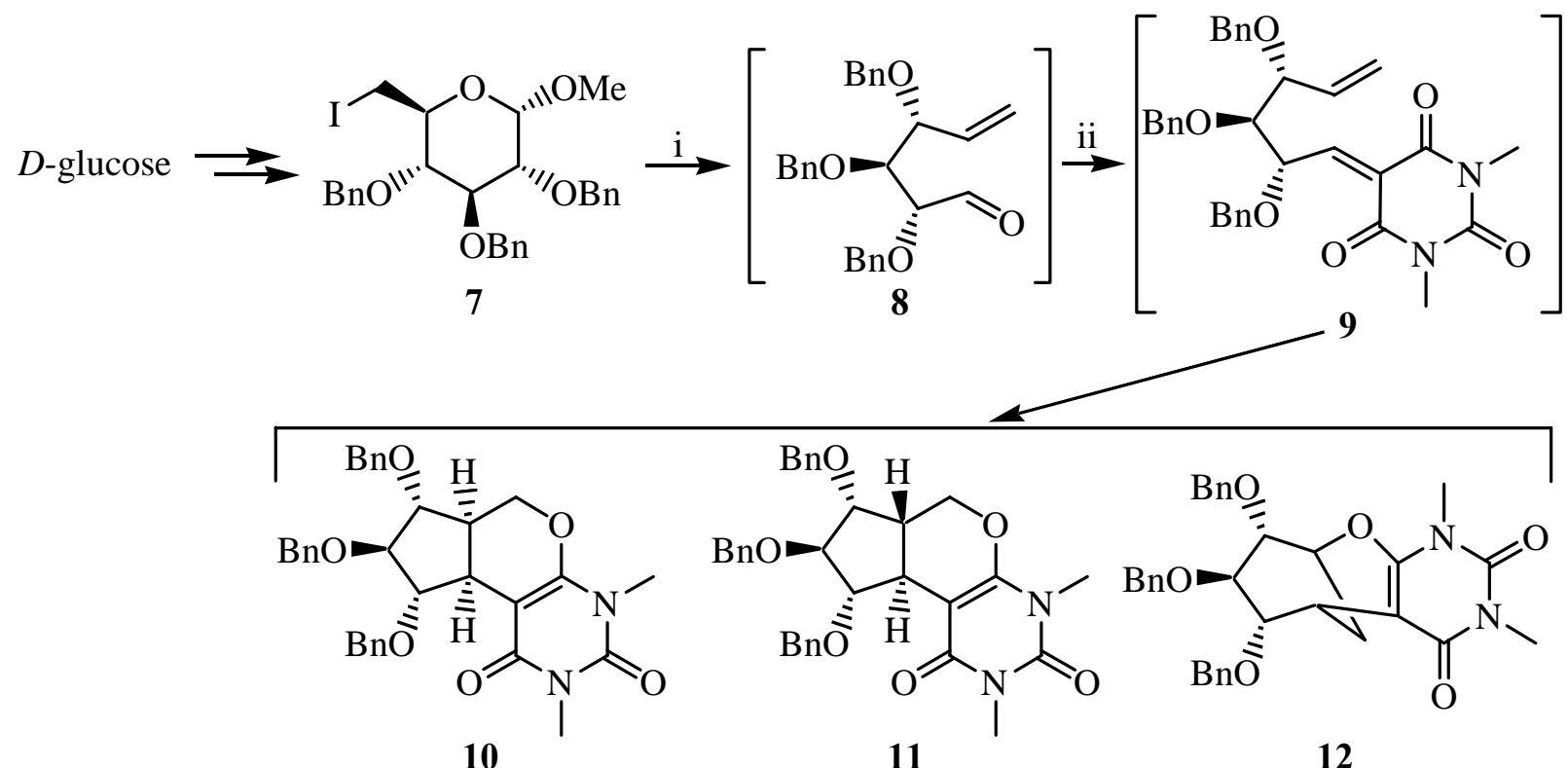

Scheme 2. DKHDA reaction of the $D$-glucose derived aldehyde 8. i. ref. 14e; ii. 4, EDDA, $\mathrm{Na}_{2} \mathrm{SO}_{4}, \mathrm{CH}_{3} \mathrm{CN}$, reflux, $47 \%$, ratio of $\mathbf{1 0 / 1 1 / 1 2}$ ca.3.4:2.8:1 (overall from 7). 


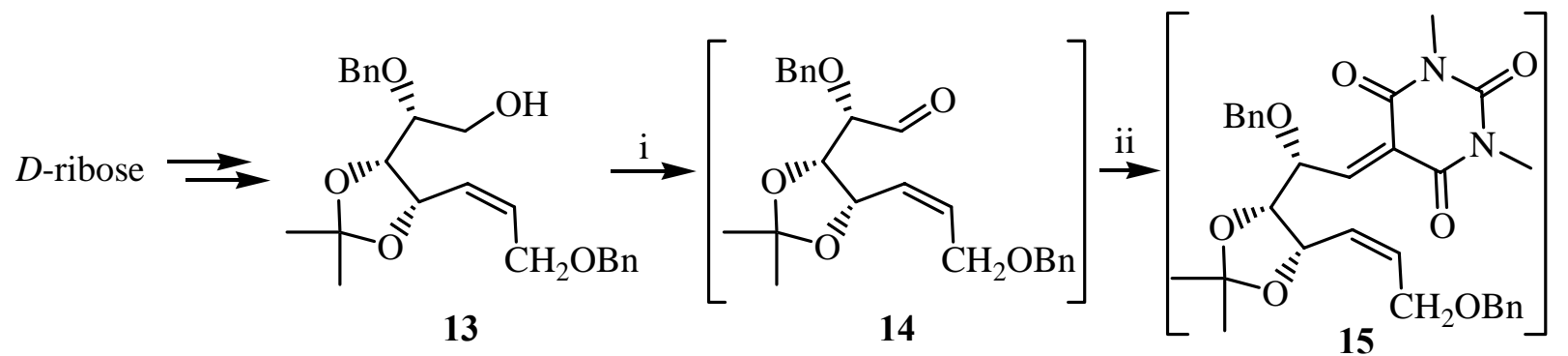<smiles>C[C@H]1Oc2c(c(=O)n(C)c(=O)n2C)[C@H]2[C@@H]1[C@H]1OC(C)(C)O[C@H]1[C@@H]2Cc1ccccc1</smiles>

16

Scheme 3. DKHDA reaction of the $D$-glucose derived aldehyde 14. i. ref. 14e; ii. 4, EDDA, $\mathrm{Na}_{2} \mathrm{SO}_{4}, \mathrm{CH}_{3} \mathrm{CN}$, reflux, $43 \%$ (overall from 13 ).

Assignment of the stereochemistry of all products isolated was made with the aid of COESY and NOESY experiments. For the case of aldehyde $\mathbf{8}$ the transition states of the intramolecular hetero Diels-Alder (HDA) reaction were studied in order to explain our findings (Scheme 4). 


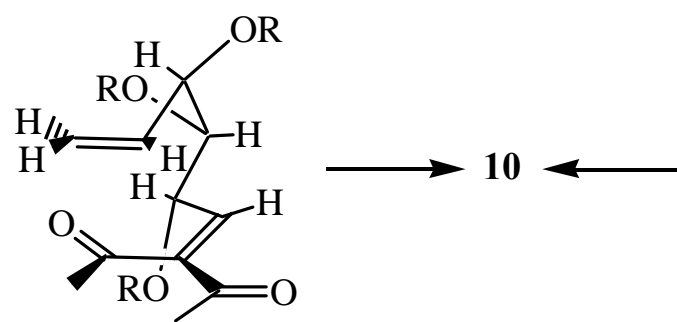

Exo-Z-syn (1)

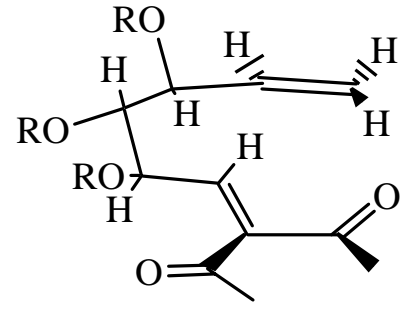

Endo-E-syn (1)

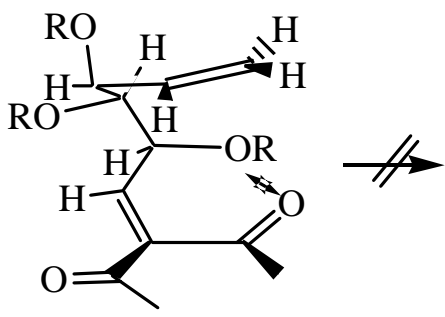

Exo-Z-syn (2)

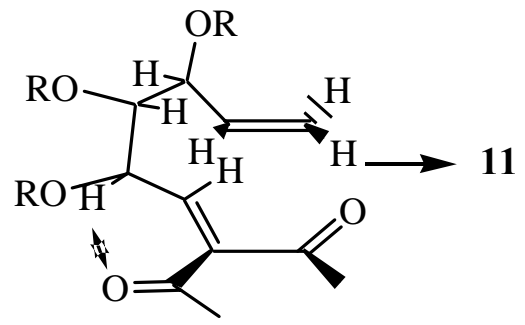

Exo-E-anti (1)

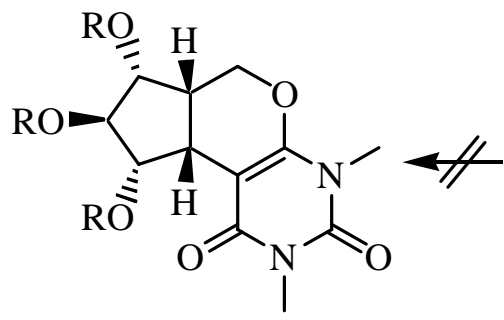

17

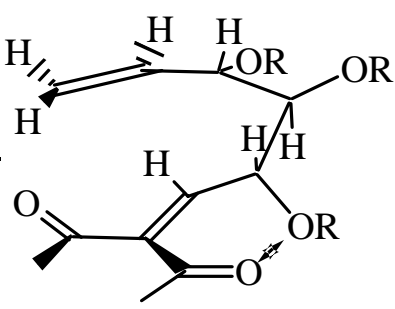

Endo-E-syn (2)

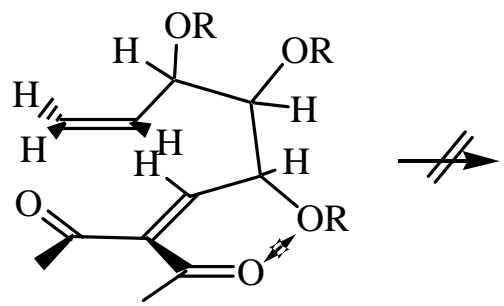

Exo-E-anti (2)

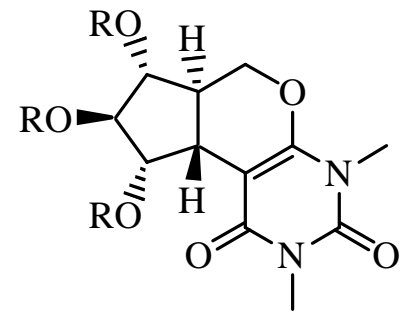

18

Scheme 4. Transition states for the intramolecular HDA reaction of $9(\mathrm{R}=\mathrm{Bn})$.

Although there is a detailed and systematic investigation dealing with the stereochemistry of six-membered fused systems, very few efforts targeted the question of which is the stereochemical outcome of reactions leading to five-membered analogous systems. ${ }^{1 b, 2,7,9}$ It seems that stereochemistry of C-2 (sugar numbering) plays a crucial role in which of the transition states will dominate. Thus, cis-product 10 could derive either from the exo-Z-syn (1) or the endoE-syn (1) approach. Formation of the diastereoisomeric cis-product 17 is highly disfavored since in the exo-Z-syn (2) or endo-E-syn (2) transition states approach of C-2 substituent with the nonreacting carbonyl group becomes important. The same steric hindrance prevents the formation of trans-product 18, whereas 11 was obtained in appreciable yield probably because of the lesser interaction between the $\mathrm{H}-2$ and the non-reacting carbonyl group. The possibility of an endo-Zanti transitional state was ruled out due to inability of the diene and dienophile to approach. ${ }^{2}$ Analogously, the exclusive formation of the regioisomeric bridged product $\mathbf{1 2}$ is justified accepting an exo-Z-syn approach. However, the small size of the carbon chain between the alkene and hetero diene moieties does not allow the formation of $\mathbf{1 2}$ in high yield. 
Substrate 15 exhibits a similar behavior but we speculate that cis-product 16 derives exclusively from the corresponding exo-Z-syn transitional state since the endo-E-syn is prohibited by the rigidity the acetonide ring imposes. Proximity of the same ring with the benzyloxymethyl substituent of the double bond seems to disfavor the exo-E-anti approach, which will allow the formation of a trans-diastereoisomer.

In contrast to the results obtained with $N, N$-dimethylbarbituric acid, Meldrum's acid, $\mathbf{5}$, failed to give cycloaddition products with $\delta, \varepsilon$-unsaturated aldehydes 8 and 14. Both substrates led, upon heating in acetonitrile, to highly complicated mixtures, which were found solely to consist of decomposition products instead to the desired ones. These unexpected findings are not in accordance with the results reported by Tietze ${ }^{2,7}$ and Takano ${ }^{9}$ where domino reactions with Meldrum's acid easily took place.

Interestingly, we were able to isolate the Knoevenagel condensation product $\mathbf{1 9}$ when the reaction between $\mathbf{8}$ and $\mathbf{5}$ was performed at ambient temperature (Scheme 5). This intermediate was purified and used in thermal or catalyzed reactions in order to achieve cycloaddition to $\mathbf{2 0 .}$ However, none of the conditions employed e.g. heating in acetonitrile or isopropyl alcohol ${ }^{9 \mathrm{c}}$ and Lewis acid catalysis ${ }^{11}$ (with $\mathrm{MgBr}_{2}, \mathrm{Et}_{2} \mathrm{AlCl}, \mathrm{BF}_{3} \mathrm{OEt}_{2}, \mathrm{ZnCl}_{2}$ and $\mathrm{SnCl}_{4}$ ) in a variety of solvents gave better results. To the best of our knowledge, this is the first Meldrum's acid system, which undoubtedly gives the Knoevenagel condensation and fails to give the intramolecular cycloaddition.

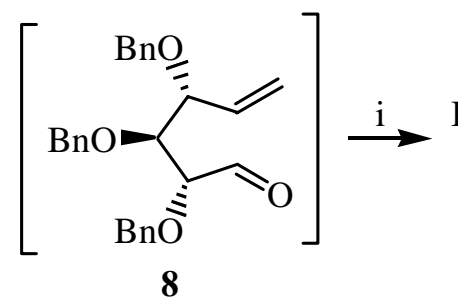

8

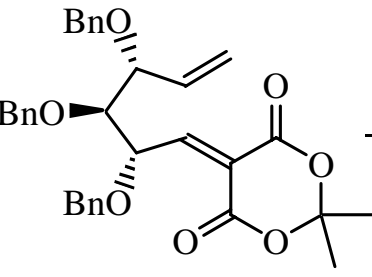

19

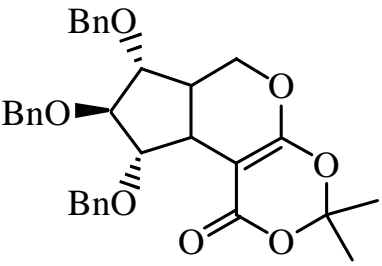

20

Scheme 5. Attempted DKHDA reaction of aldehyde 8 with Meldrum's acid. i. 5, EDDA, $\mathrm{Na}_{2} \mathrm{SO}_{4}, \mathrm{CH}_{3} \mathrm{CN}, 25{ }^{\circ} \mathrm{C}$, 82\% from iodide 7; ii. various conditions, see text.

Reactions with dimedone, 6, were also investigated. Lower reactivity for this 1,3-dicarbonyl component was expected and was indeed observed since all reactions run gave no cycloaddition products. In fact, similar results were obtained by Vasella's group ${ }^{15}$ when DKHDA reaction of 8 to 6 was attempted leading to a double addition of dimedone to the unsaturated aldehyde.

\section{Conclusions}

The intramolecular domino Knoevenagel hetero Diels-Alder reaction could be used as an exceptional approach towards the preparation of fused polyhydroxylated carbocycles in an easy and efficient way. Our initial goal was to demonstrate the feasibility of this plan. Systematic 
study of the rules governing the stereochemical outcome of these reactions with different substrates and employment of products derived from simple 1,3-dicarbonyl components in synthetic schemes leading to other equally interesting products, through the appropriate transformations (e.g. from $N, N$-dimethylbarbituric acid ${ }^{8 \mathrm{~m}}$ ), will be certainly part of our research program.

\section{Experimental Section}

General Procedures. All reactions were carried out under a nitrogen atmosphere with dry and freshly distilled solvents under anhydrous conditions. Yields refer to chromatographically and spectroscopically homogeneous materials, unless otherwise stated. Column chromatography was performed on silica gel (Kieselgel 60, 70-230 mesh). Preparative thin layer chromatography (PTLC) was performed on $0.25 \mathrm{~mm}$ E. Merck silica gel plates (60F-254). $R_{f}$ values were measured using the indicated eluent on silica gel plates (60F-254) using UV light or $p$ anisaldehyde solution for visualization. HRMS were recorded on a VG ZAB-ZSE mass spectrometer under FAB conditions with NBA as the matrix. ${ }^{1} \mathrm{H}$ NMR spectra were recorded at 300 or $600 \mathrm{MHz}$ on a Bruker $300 \mathrm{AM}$ or a Bruker DRX-600 spectrometer, respectively. ${ }^{13} \mathrm{C}$ NMR spectra were recorded at $75 \mathrm{MHz}$ on a Bruker 300 AM spectrometer. All NMR experiments were carried out using tetramethylsilane as an internal standard. IR spectra were recorded on a Perkin Elmer 297 instrument. Optical rotations were measured at $25{ }^{\circ} \mathrm{C}$ on an A. Krüss P3000 Automatic Digital Polarimeter.

DKHDA reaction of $(2 \mathrm{R}, 3 \mathrm{~S}, 4 \mathrm{R})-2,3,4$-tris-benzyloxy-hex-5-enal (8) with $N, N$ dimethylbarbituric acid (4). Aldehyde 8 was prepared from iodide 7 (580 $\mathrm{mg}, 1 \mathrm{mmol}$ ) according to the literature. ${ }^{14 \mathrm{e}}$ After removal of solids by filtration and the solvent under reduced pressure the residue was dried thoroughly under high vacuum for several hours. Then, acetonitrile $(10 \mathrm{ml})$ was added followed by 4 (170 mg, $1.1 \mathrm{mmol})$, EDDA (10 mg) and anhydrous $\mathrm{Na}_{2} \mathrm{SO}_{4}$ (500 mg). The mixture was heated to reflux until TLC indicated the consumption of starting material (about 3 hours). The solvent was removed under reduced pressure and the mixture was purified by column chromatography using $25 \%$ ethyl acetate in hexanes as eluent to afford products 10 and 11 (230 mg, 41\% overall from 7, as a mixture) and their regioisomer $\mathbf{1 2}$ (36 mg, 6\% overall from 7). The mixture of $\mathbf{1 0}$ and $\mathbf{1 1}$ was further purified using PTLC with 15\% ethyl acetate in benzene as eluent to yield pure samples of 10 (125 mg) and 11 (100 mg).

(1S,2R,3R,3aR,9bS)-1,2,3-Tris-benzyloxy-6,8-dimethyl-2,3,3a,4,6,9b-hexahydro-1H-5-oxa6,8-diaza-cyclopenta[a]naphthalene-7,9-dione (10). Oil; $R_{f}$ : 0.33 (50\% ethyl acetate in hexanes); $[\alpha]_{\mathrm{D}}$ : -2.8 (c 1, $\mathrm{CHCl}_{3}$ ); IR (neat): 3070, 3030, 2940, 2900, 1700, $1635 \mathrm{~cm}^{-1} ;{ }^{1} \mathrm{H} \mathrm{NMR}$ (600 MHz, $\mathrm{C}_{6} \mathrm{D}_{6}$ ): 7.65 (d, $\left.J=7.0 \mathrm{~Hz}, 2 \mathrm{H}\right), 7.29-7.05$ (m, 13H), 5.28 (d, $\left.J=12.3 \mathrm{~Hz}, 1 \mathrm{H}\right), 5.14$ (d, $J=12.3 \mathrm{~Hz}, 1 \mathrm{H}), 4.77$ (d, $J=12.0 \mathrm{~Hz}, 1 \mathrm{H}), 4.57$ (d, $J=12.0 \mathrm{~Hz}, 1 \mathrm{H}), 4.49$ (d, $J=1.8 \mathrm{~Hz}$, 1H), 4.46 (d, $J=11.8 \mathrm{~Hz}, 1 \mathrm{H}), 4.32$ (d, $J=11.8 \mathrm{~Hz}, 1 \mathrm{H}), 4.26$ (bd, $J=6.2 \mathrm{~Hz}, 1 \mathrm{H}), 3.96$ (dd, $J=$ 
11.1, $1.6 \mathrm{~Hz}, 1 \mathrm{H}$ ), 3.94 (dd, $J=10.3,6.4 \mathrm{~Hz}, 1 \mathrm{H}$ ), 3.26 (s, 3H), 3.18 (dd, $J=11.0,2.2 \mathrm{~Hz}, 1 \mathrm{H}$ ), 3.01 (d, $J=7.9 \mathrm{~Hz}, 1 \mathrm{H}), 2.77$ (s, 3H), 2.45 (bdd, $J=10.2,7.9 \mathrm{~Hz}, 1 \mathrm{H})$ ) ${ }^{13} \mathrm{C}$ NMR $(75 \mathrm{MHz}$, $\left.\mathrm{CDCl}_{3}\right)$ : 161.6, 155.2, 149.8, 138.0, 136.9, 136.7, 128.0, 127.4, 127.3, 127.2, 126.8, 126.7, 126.5, 126.3, 126.2, 90.0, 80.4, 76.4, 75.8, 71.3, 71.2, 70.6, 68.3, 38.8, 27.6, 27.0, 26.8; HRMS: 554.2420 (calculated for $\mathrm{C}_{33} \mathrm{H}_{34} \mathrm{~N}_{2} \mathrm{O}_{6}$ : 554.2417).

(1S,2R,3R,3aS,9bS)-1,2,3-Tris-benzyloxy-6,8-dimethyl-2,3,3a,4,6,9b-hexahydro-1H-5-oxa6,8-diaza-cyclopenta[a]naphthalene-7,9-dione (11). Oil; $R_{f}$ : 0.33 (50\% ethyl acetate in hexanes); $[\alpha]_{\mathrm{D}}$ : -2.0 (c 1, $\mathrm{CHCl}_{3}$ ); IR (neat): 3075, 3030, 2930, 2900, 1700, $1640 \mathrm{~cm}^{-1} ;{ }^{1} \mathrm{H} \mathrm{NMR}$ (600 MHz, $\mathrm{C}_{6} \mathrm{D}_{6}$ ): 7.43 (d, $\left.J=7.4 \mathrm{~Hz}, 2 \mathrm{H}\right), 7.28-7.03$ (m, 13H), 4.81 (d, $\left.J=12.2 \mathrm{~Hz}, 1 \mathrm{H}\right), 4.68$ (d, $J=12.2 \mathrm{~Hz}, 1 \mathrm{H}), 4.38$ (d, $J=11.8 \mathrm{~Hz}, 1 \mathrm{H}), 4.35$ (bs, 1H), 4.32 (d, $J=11.4 \mathrm{~Hz}, 1 \mathrm{H}), 4.30$ (d, $J=11.9 \mathrm{~Hz}, 1 \mathrm{H}$ ), 4.21 (d, $J=11.4 \mathrm{~Hz}, 1 \mathrm{H}$ ), 3.96 (bs, $1 \mathrm{H}$ ), 3.61 (bt, $J=3.9 \mathrm{~Hz}, 1 \mathrm{H}$ ), 3.50 (bs, 1H), 3.43 (bs, 1H), 3.34 (s, 3H), 2.89 (s, 3H), 2.37 (dt, $J=13.6,1.8 \mathrm{~Hz}, 1 \mathrm{H}), 1.20$ (bd, $J=13.6$ $\mathrm{Hz}, 1 \mathrm{H}) ;{ }^{13} \mathrm{C} \mathrm{NMR}\left(75 \mathrm{MHz}, \mathrm{CDCl}_{3}\right.$ ): 161.2, 155.4, 149.8, 137.6, 137.3, 136.7, 127.5, 127.4, 127.3, 127.0, 126.9, 126.7, 126.5, 126.4, 126.1, 86.3, 83.5, 76.2, 75.6, 71.3, 70.9, 70.4, 70.3, 35.4, 27.3, 27.0, 25.1; HRMS: 554.2415 (calculated for $\mathrm{C}_{33} \mathrm{H}_{34} \mathrm{~N}_{2} \mathrm{O}_{6}$ : 554.2417).

(1R,9S,10R,11R,12S)-10,11,12-Tris-benzyloxy-4,6-dimethyl-8-oxa-4,6-diaza-tricyclo[7.3.1.0 $\left.{ }^{\mathbf{2 , 7}}\right]$ tridec-2(7)-ene-3,5-dione (12). Oil; $R_{f}: 0.11$ (50\% ethyl acetate in hexanes); $[\alpha]_{\mathrm{D}}:-3.8$ (c 1, $\mathrm{CHCl}_{3}$ ); IR (neat): 3050, 3020, 2920, 2850, 1690, $1620 \mathrm{~cm}^{-1} ;{ }^{1} \mathrm{H}$ NMR (300MHz, $\left.\mathrm{CDCl}_{3}\right): 7.45$ (dd, $J=7.3,2.0 \mathrm{~Hz}, 2 \mathrm{H}), 7.35-7.25$ (m, 13H), 5.13 (d, $J=11.4 \mathrm{~Hz}, 1 \mathrm{H}), 4.84$ (d, $J=10.5 \mathrm{~Hz}$, 1H), 4.76 (bs, 2H), 4.72 (d, $J=10.5 \mathrm{~Hz}, 1 \mathrm{H}), 4.61$ (d, $J=11.4 \mathrm{~Hz}, 1 \mathrm{H}), 3.67-3.62$ (m, 2H), 3.593.50 (m, 2H), 3.40 (s, 3H), 3.38-3.35 (m, 1H), 3.37 (s, 3H), 1.90 (dt, $J=14.1,3.8 \mathrm{~Hz}, 1 \mathrm{H}), 1.68$ (bd, $J=14.2 \mathrm{~Hz}, 1 \mathrm{H}) ;{ }^{13} \mathrm{C} \mathrm{NMR}\left(75 \mathrm{MHz} \mathrm{CDCl}_{3}\right.$ ): 162.5, 156.0, 151.1, 138.8, 138.5, 138.1, 128.53, 128.50, 128.3, 128.0, 127.9, 127.7, 127.5, 87.5, 83.8, 83.5, 81.9, 76.3, 75.6, 72.6, 71.6, 28.8, 28.2, 25.9, 23.7; HRMS: 554.2421 (calculated for $\mathrm{C}_{33} \mathrm{H}_{34} \mathrm{~N}_{2} \mathrm{O}_{6}$ : 554.2417).

DKHDA reaction of (2S,3S,4S)-2,7-bis-benzyloxy-3,4-isopropylidenedihydroxy-hept-5-enal (14) with $N, N$-dimethylbarbituric acid (4). Aldehyde 14 was prepared from alcohol 13 (400 $\mathrm{mg}, 1 \mathrm{mmol}$ ) according to the literature. ${ }^{14 \mathrm{e}}$ After aqueous workup the solvent was removed under reduced pressure and the residue was dried thoroughly under high vacuum for several hours. Then, acetonitrile $(10 \mathrm{ml})$ was added followed by 4 (170 mg, $1.1 \mathrm{mmol})$, EDDA (10 mg) and anhydrous $\mathrm{Na}_{2} \mathrm{SO}_{4}$ (500 mg). The mixture was heated to reflux until TLC indicated the consumption of starting material (about 4 hours). The solvent was removed under reduced pressure and the mixture was purified by column chromatography using $25 \%$ ethyl acetate in hexanes as eluent to afford product 16 (230 mg, 43\% overall from 13, as an inseparable mixture with two other unidentified minor products).

(1R,2R,3S,3aS,4R,9bR)-1-Benzyloxy-4-benzyloxymethyl-2,3-isopropylidenedihydroxy-6,8dimethyl-2,3,3a,4,6,9b-hexahydro-1H-5-oxa-6,8-diaza-cyclopenta[a]naphthalene-7,9-dione (16). Oil; $R_{f}$ : 0.38 (50\% ethyl acetate in hexanes); IR (neat, mixture of products): 3050, 3010, 2960, 2850, 1700-1640 (broad) $\mathrm{cm}^{-1}$; ${ }^{1} \mathrm{H}$ NMR (signal set of major isomer, 16, $300 \mathrm{MHz}$, $\mathrm{CDCl}_{3}$ ): 7.42 (d, $\left.J=7.2 \mathrm{~Hz}, 2 \mathrm{H}\right), 7.38-7.29(\mathrm{~m}, 7 \mathrm{H}), 7.27-7.22(\mathrm{~m}, 1 \mathrm{H}), 4.89$ (d, $J=11.9 \mathrm{~Hz}$, 1H), 4.73 (d, $J=11.9 \mathrm{~Hz}, 1 \mathrm{H}), 4.63$ (bs, 2H), 4.57 (dd, $J=7.4,4.9 \mathrm{~Hz}, 1 \mathrm{H}), 4.47$ (d, $J=4.7 \mathrm{~Hz}$, 
1H), 4.42 (d, $J=4.5 \mathrm{~Hz}, 1 \mathrm{H}), 4.37-4.34$ (m, 1H), 3.95 (dd, $J=11.0,7.7 \mathrm{~Hz}, 1 \mathrm{H}), 3.83$ (dd, $J=$ 10.9, $3.6 \mathrm{~Hz}, 1 \mathrm{H}), 3.36$ (s, 3H), 3.31 (s, 3H), 2.96-2.91 (m, 1H), 1.53 (s, 3H), 1.31 (s, 3H), 0.900.83 (m, 1H); ${ }^{13} \mathrm{C}$ NMR (signal set of major isomer, 16, $75 \mathrm{MHz}, \mathrm{CDCl}_{3}$ ): 162.1, 156.4, 150.6, 139.1, 137.6, 128.4, 128.1, 127.8, 127.5, 127.2, 127.0, 114.7, 86.2, 81.4, 78.9, 78.8, 78.5, 73.4, 72.8, 70.5, 43.07, 43.00, 28.71, 27.8, 26.2, 25.5; HRMS: 534.2369 (calculated for $\mathrm{C}_{30} \mathrm{H}_{34} \mathrm{~N}_{2} \mathrm{O}_{7}$ : 534.2366).

Knoevenagel condensation of $(2 \mathrm{R}, 3 \mathrm{~S}, 4 \mathrm{R})-2,3,4$-tris-benzyloxy-hex-5-enal (8) with Meldrum's acid (5). Aldehyde 8 was prepared from iodide 7 (580 mg, $1 \mathrm{mmol}$ ) according to the literature. ${ }^{14 \mathrm{e}}$ After removal of solids by filtration and the solvent under reduced pressure the residue was dried thoroughly under high vacuum for several hours. Then, acetonitrile (10 ml) was added followed by 5 (160 mg, $1.1 \mathrm{mmol})$, EDDA (10 mg) and anhydrous $\mathrm{Na}_{2} \mathrm{SO}_{4}$ (500 mg). The mixture was left with stirring at room temperature until TLC indicated the consumption of starting material (about 2 hours). The solvent was removed under reduced pressure at ambient temperature and the mixture was purified by column chromatography using $20 \%$ ethyl acetate in hexanes as eluent to afford the condensation product 19 (445 mg, 82\% overall from 7).

(2S,3S,4R)-2,2-Dimethyl-5-(2,3,4-tris-benzyloxy-hex-5-enylidene)-[1,3]dioxane-4,6-dione (19). Oil; $R_{f}: 0.60$ (20\% ethyl acetate in hexanes); [ $\left.\alpha\right]_{\mathrm{D}}$ : -3.3 (c 1, $\mathrm{CHCl}_{3}$ ); IR (neat): 3075, 3020, 2930, 2850, 1760, 1725, $1625 \mathrm{~cm}^{-1}$; ${ }^{1} \mathrm{H}$ NMR (300 MHz, $\mathrm{CDCl}_{3}$ ): 7.79 (d, $\left.J=8.1 \mathrm{~Hz}, 1 \mathrm{H}\right), 7.39-7.24$ (m, 15H), 5.89 (ddd, $J=17.7,9.9,7.8 \mathrm{~Hz}, 1 \mathrm{H}$ ), 5.38-5.28 (m, 3H), 4.65 (d, $J=18.9$; $11.0 \mathrm{~Hz}$, 1H), 4.58 (d, $J=11.0 \mathrm{~Hz}, 1 \mathrm{H}), 4.58$ (d, $J=12.6 \mathrm{~Hz}, 1 \mathrm{H}), 4.54$ (d, $J=11.9 \mathrm{~Hz}, 1 \mathrm{H}), 4.44$ (d, $J=$ $11.9 \mathrm{~Hz}, 1 \mathrm{H}$ ), 4.41 (d, $J=12.6 \mathrm{~Hz}, 1 \mathrm{H}), 4.29$ (t, $J=7.1 \mathrm{~Hz}, 1 \mathrm{H}), 3.81$ (dd, $J=6.3,3.9 \mathrm{~Hz}, 1 \mathrm{H}$ ),

1.52 (s, 3H), 1.41 (s, 3H); ${ }^{13} \mathrm{C}$ NMR (75 MHz, $\mathrm{CDCl}_{3}$ ): 167.3, 160.7, 160.0, 138.2, 137.6, 137.4, 135.1, 129.2, 128.5, 128.40, 128.36, 128.24, 128.20, 128.1, 127.8, 127.6, 119.7, 117.6, 105.0, 82.8, 81.3, 76.0, 74.9, 73.3, 70.8, 27.6, 27.3; HRMS: 542.2314 (calculated for $\mathrm{C}_{33} \mathrm{H}_{34} \mathrm{O}_{7}$ : 542.2305).

\section{References}

1. (a) Ho, T. L. Tandem Organic Reactions; Wiley: New York, 1992. (b) Tietze, L. F.; Beifuss, U. Angew. Chem., Int. Ed. 1993, 32, 131.

2. Tietze, L. F. Chem. Rev. 1996, 96, 115 and references cited there in.

3. Tietze, L. F.; Modi, A. Med. Res. Rev. 2000, 20, 304.

4. (a) Tietze, L. F.; Kettschau, G.; Gewert, J. A.; Schuffenhauer, A. Curr. Org. Chem. 1998, 2, 19. (b) Tietze, L. F.; Kettschau, G. Top. Curr. Chem. 1997, 189, 1.

5. (a) Jones, G. Org. React. 1967, 15, 204. (b) Tietze, L. F.; Beifuß, U. Comprehensive Organic Synthesis, Trost B. M., Ed.; Vol. 2, Pergamon Press: New York, 1991.

6. Boger, D. L.; Weinreb, S. M. Hetero Diels-Alder Methodology in Organic Synthesis, Academic Press: San Diego, 1987.

7. Tietze, L. F. J. Heterocyclic Chem. 1990, 27, 47 and references cited there in. 
8. (a) Tietze, L. F.; von Kiedrowski, G. Tetrahedron Lett. 1981, 22, 219. (b) Tietze, L. F.; Beifuss, U.; Lökös, M.; Rischer, M.; Göhrt, A.; Scheldrick G. M. Angew. Chem., Int. Ed. 1990, 29, 527. (c) Tietze, L. F.; von Kiedrwski, G.; Fahlbusch, K.-G.; Voss, E. Org. Synth. 1990, 69, 31. (d) Tietze, L. F.; Wölfling J.; Schnider, G. Chem. Ber. 1991, 124, 591. (e) Tietze, L. F.; Ott, C.; Gerke, K.; Buback, M. Angew. Chem., Int. Ed. 1993, 32, 1485. (f) Buback, M.; Gerke, K.; Ott, C.; Tietze, L. F. Chem. Ber. 1994, 127, 2241. (g) Buback, M.; Abeln, J.; Hübsch, T.; Ott, C.; Tietze, L. F. Liebigs Ann. Chem. 1995, 9. (h) Tietze, L. F.; Hippe, T.; Steinmetz, A. Synlett 1996, 1043. (i) Tietze, L. F.; Steinmetz, A. Angew. Chem., Int. Ed. 1996, 35, 651. (i) Tietze, L. F.; Steinmetz, A.; Balkenhohl, F. Bioorg. Med. Chem. Lett. 1997, 7, 1303. (j) Tietze, L. F.; Bachmann J.; Wichmann, J.; Zhou, Y.; Raschke, T. Liebigs Ann. Chem. 1997, 881. (k) Tietze, L. F.; Pfeiffer, T.; Schuffenhauer, A. Eur. J. Org. Chem. 1998, 2733. (l) Tietze, L. F.; Zhou, Y. Angew. Chem., Int. Ed. 1999, 38, 2045. (m) Tietze, L. F.; Ott, C.; Geißler, H.; Haunert, F. Eur. J. Org. Chem. 2001, 1625.

9. (a) Takano, S. Pure Appl. Chem. 1987, 59, 353. (b) Takano, S.; Ohkawa, T.; Tamori, S.; Satoh, S.; Ogasawara, K. J. Chem. Soc. Chem. Commun. 1988, 189. (c) Takano, S.; Satoh, S.; Ogasawara, K. J. Chem. Soc., Chem. Commun. 1988, 59. (d) Takano, S.; Satoh, S.; Ogasawara, K. Heterocycles 1990, 30, 583. (e) Takano, S.; Satoh, S.; Ogasawara, K. Heterocycles 1985, 23, 41.

10. (a) Snider, B. B.; Lu, Q. Tetrahedron Lett. 1994, 35, 531. (b) Snider, B. B.; Lu, Q. J. Org. Chem. 1996, 61, 2839.

11. Hiroi, K.; Umemura, M.; Fujisawa, A. Tetrahedron Lett. 1992, 33, 7161.

12. (a) Ceulemans, E.; Voets, M.; Emmers, S.; Uytterhoven, K.; Van Meervelt, L.; Dehaen, W. Tetrahedron 2002, 58, 531. (b) Ceulemans, E.; Voets, M.; Emmers, S.; Dehaen, W. Synlett 1997, 1155.

13. (a) Shanmugasundaram, M.; Manikandan, S.; Raghunathan, R. Tetrahedron 2002, 58, 997. (b) Manikandan, S.; Shanmugasundaram, M.; Raghunathan, R. Tetrahedron 2002, 58, 8957.

14. (a) Gallos, J. K.; Koftis, T. V.; Koumbis, A. E. J. Chem. Soc., Perkin Trans. 1 1994, 611. (b) Gallos, J. K.; Goga, E. G.; Koumbis, A. E. J. Chem. Soc., Perkin Trans. 1 1994, 613. (c) Gallos, J. K.; Koumbis, A. E.; Apostolakis, N. E. J. Chem. Soc., Perkin Trans. 1 1997, 2457. (d) Gallos, J. K.; Koftis, T. V.; Karamitrou, V. I.; Koumbis, A. E. J. Chem. Soc. Perkin Trans. 1 1997, 2461. (e) Gallos, J. K.; Koumbis, A. E.; Xiraphaki, V. P.; Dellios C. C.; Koumbis, A. E.; Coutouli-Argyropoulou, E. Tetrahedron 1999, 55, 15167. (f) Gallos, J. K.; Koftis, T. V.; Koumbis, A. E.; Moutsos V. I. Synlett 1999, 1289. (g) Gallos, J. K.; Koftis, T. V.; Sarli, V. C.; Litinas, K. E. J. Chem. Soc., Perkin Trans. 1 1999, 3075. (h) Gallos, J. K.; Dellios, C. C.; Spata, E. E. Eur. J. Org. Chem. 2001, 79. (i) Gallos, J. K.; Damianou, K. C.; Dellios C. C. Tetrahedron Lett. 2001, 42, 5769. (j) Gallos, J. K.; Koftis, T. V. J. Chem. Soc., Perkin Trans. 1 2001, 415. (k) Gallos, J. K.; Massen, Z. S.; Koftis, T. V.; Dellios, C. C. Tetrahedron Lett. 2001, 42, 7489. (l) Gallos, J. K.; Koftis, T. V.; Massen, Z. S.; Dellios C. C.; Mourtzinos, I. T.; Coutouli-Argyropoulou, E.; Koumbis, A. E. Tetrahedron 2002, 58, 8043.

15. Bernet, B.; Vasella, A. Helv. Chim. Acta 1979, 62, 1990. 